\title{
Computational airblast modelling of commercial explosives
}

\author{
B. J. Zapata \& D. C. Weggel \\ Department of Civil and Environmental Engineering, UNC Charlotte, \\ USA
}

\begin{abstract}
Two separate blast tests were conducted inside a conventional, unreinforced, brick building scheduled to be demolished. The small cylindrical explosive charges (less than $9 \mathrm{~kg}$ each), composed of dynamite sticks bundled together, were placed inside the building and detonated (in separate events) to study the blast resistance of the structure. The pressures generated by the blasts were recorded using a high speed data acquisition system. To better understand the complex pressure loading caused by the blasts for use in structural response modelling, the authors have undertaken a study to computationally model the explosive detonations. Advanced computational modelling is of interest because most tabular and other simplified blast load analysis techniques are inaccurate for the case of a close-in (but outside the detonation products) blast produced by a cylindrical charge. This paper presents the results of two dimensional airblast simulations performed using CTH, a shock physics code written by Sandia National Laboratories. The Jones-Wilkins-Lee (JWL) equation of state data for dynamite available in the literature are reviewed and the equation coefficients are adjusted to reflect the properties of the dynamite used in the tests. CTH simulations are compared to the measured blast pressures and impulses to assess the ability of the existing (adjusted) equation of state data to model currently available commercial dynamite.
\end{abstract}

Keywords: explosives, equation of state, airblast, bomb blast, impact and blast loading characteristics, interaction between computational and experimental results. 


\section{Introduction}

The Department of Civil and Environmental Engineering at the University of North Carolina at Charlotte conducted two blast tests inside a conventional, unreinforced, brick building before its scheduled demolition. The experimental program was designed to serve two purposes. The first purpose was to study the blast performance of a non-purpose-built, conventional brick building that, by definition, possessed representative dead loads, non-ideal boundary conditions, and the inherent characteristics resulting from the design and construction practices in the United States in the 1940s. The second purpose of the experiment was to study the capabilities of various analytical techniques to predict blast pressures for close-in, non-hemispherical (or non-spherical) charges.

This scenario is of interest because it results in non-planar blast waves as opposed to the planar blast waves generated by distant explosions. USACE [1] contains guidance for the analysis of blast loads generated by cylindrical charges, but this data is only tabulated for a few explosives relevant to military weaponry. Data has not been generated for commercial explosives such as the dynamite used in this work. Typically, defense laboratories or the Department of Energy in the United States are tasked with characterizing explosives to support ongoing weapons related programs. Within the government explosives community, the characterization of an explosive is typically project specific, and dynamite is not widely used for military applications because more powerful and stable explosives are readily available. While the use of precisely manufactured TNT would have simplified the selection of explosive properties and the associated equation of state to accurately model airblast effects, logistical considerations led the authors to use dynamite in this experimental program.

This article reports the results of an analytical and experimental program in which sticks of commercial dynamite (Unimax, Dyno Nobel, Salt Lake City, Utah) were bundled together and detonated in two separate blast events. First, equation of state data available in the literature for commercial dynamites is reviewed. This data will be modified using a density scaling technique to develop coefficients for the Jones-Wilkins-Lee (JWL) equation of state for a previously uncharacterized dynamite, Unimax. The adjusted JWL coefficients will be used with CTH, a shock physics computer code written by Sandia National Laboratories, to simulate the airblast created by the dynamite charges. The simulations will be used to assess the adequacy of the new JWL coefficients for Unimax by comparing simulation pressures and impulses to experimental pressures and impulses.

\section{Commercial dynamite in the United States}

Dyno Nobel is the only manufacturer of nitroglycerin dynamites in North America today. In the 1980's there were still several nitroglycerin dynamite manufacturers as evidenced by Cooper [2]. Of the commercially manufactured dynamites, Unigel (made by Hercules) was widely considered the standard 
gelatin dynamite. Dyno Nobel acquired Hercules in 1985 and began manufacturing Unigel as their own product. With the rising use of bulk explosives like ANFO, the demand for dynamites decreased and Dyno Nobel became the sole manufacturer of nitroglycerin dynamites in North America.

Dyno Nobel currently manufactures two main nitroglycerin dynamite products, Unigel and Unimax. Their energetic and chemical properties are shown in Table 1. No test data was available regarding detonation pressure, so eqn (1) was used to compute it assuming the adiabatic gamma $(\Gamma)$ was equal to 2.49 .

$$
P_{C J}=\frac{\rho_{o} D_{C J}^{2}}{(\Gamma+1)}
$$

In this equation $\rho_{\mathrm{o}}$ is the explosive's unreacted density and $\mathrm{D}_{\mathrm{CJ}}$ is the detonation velocity. The Unigel currently manufactured by Dyno Nobel is similar in density to that manufactured at the time of previous studies by other authors (see Table 2). In addition to Unigel, Dyno Nobel manufactures a more powerful dynamite called Unimax. Unimax is termed an extra gelatin dynamite by the manufacturer. The designation "extra" means that the composite explosive contains additional oxidizers. The "gelatin" designation refers to the nitroglycerin component which is combined with another agent to form a gel (Cooper [2]).

The primary quantities of interest when characterizing any explosive are the unreacted density and the two Chapman Jouguet (CJ) state parameters: detonation velocity and detonation pressure. Table 2 shows that while Unigel's density has not varied considerably, there is a discrepancy between the manufacturer's detonation velocity (shown in Table 1) and that obtained by other researchers. It should be noted that Unigel's detonation velocity in Table 1 was provided by the manufacturer as a minimum while Unimax's detonation velocity was experimentally determined by the manufacturer. This could partially explain the discrepancy between the two tables.

In addition to knowing the CJ state parameters for an explosive, an equation of state (EOS) is required to computationally model a blast. The Jones-WilkinsLee (JWL) EOS is one of the most commonly used due to its simplicity. The

Table 1: $\quad$ Properties of Dyno Nobel dynamites from LeVan [3].

\begin{tabular}{|c|c|c|}
\hline & Unimax & Unigel \\
\hline Detonation Velocity $\left(\mathbf{D}_{\mathbf{C J}}\right)$ & $5856 \mathrm{~m} / \mathrm{s}$ & $4300 \mathrm{~m} / \mathrm{s}^{*}$ \\
\hline Detonation Pressure $\left(\mathbf{P}_{\mathbf{C J}}\right)$ & $14.7 \mathrm{GPa} * *$ & $6.89 \mathrm{GPa} * *$ \\
\hline Unreacted Density $\left(\boldsymbol{~}_{\mathbf{0}}\right)$ & $1.50 \mathrm{~g} / \mathrm{cc}$ & $1.30 \mathrm{~g} / \mathrm{cc}$ \\
\hline Relative Weight Strength & 1.20 & 1.09 \\
\hline Nitroglycerin Ether Extract & $26.2 \%$ & $19.5 \%$ \\
\hline Ammonium Nitrate & $39.2 \%$ & $67.0 \%$ \\
\hline Sodium Nitrate & $25.6 \%$ & $7.40 \%$ \\
\hline Heat of Explosion $(\approx$ energy) & $6.322 \mathrm{~kJ} / \mathrm{cc}$ & $5.191 \mathrm{~kJ} / \mathrm{cc}$ \\
\hline
\end{tabular}

*Unigel's detonation velocity from Dyno Nobel proprietary computer code.

**Values computed using eqn (1). 
Table 2: $\quad$ Summary of CJ parameters for dynamites from other researchers.

\begin{tabular}{|c|c|c|c|c|c|}
\hline $\begin{array}{c}\text { Product } \\
\text { Description }\end{array}$ & $\begin{array}{c}\boldsymbol{\rho}_{\mathbf{0}} \\
(\mathbf{g} / \mathbf{c c})\end{array}$ & $\begin{array}{c}\mathbf{P}_{\mathbf{C J}} \\
(\mathbf{G P a})\end{array}$ & $\begin{array}{c}\mathbf{D}_{\mathbf{C J}} \\
(\mathbf{m} / \mathbf{s})\end{array}$ & $\begin{array}{c}\text { Diameter } \\
(\mathbf{m m})\end{array}$ & Ref. \\
\hline Unigel & 1.26 & 12.8 & 5760 & $\mathrm{~N} / \mathrm{A}$ & {$[4]$} \\
\hline Unigel & 1.294 & 12.0 & 5477 & $\mathrm{~N} / \mathrm{A}$ & {$[5]$} \\
\hline Unigel & 1.262 & 12.0 & 5760 & $\mathrm{~N} / \mathrm{A}$ & {$[6]$} \\
\hline $\begin{array}{c}\text { Gelatin } \\
\text { Dynamite }\end{array}$ & 1.50 & $15.9^{*}$ & 6090 & 100 & {$[7]$} \\
\hline $\begin{array}{c}\text { Permissible } \\
\text { Dynamite }\end{array}$ & 1.10 & $2.26^{*}$ & 2680 & 45 & {$[7]$} \\
\hline $\begin{array}{c}\text { Ammonia Gelatin } \\
\text { Dynamite }\end{array}$ & 1.50 & $15.4^{*}$ & 5980 & 100 & {$[8]$} \\
\hline Extra Dynamite & 1.36 & $6.55^{*}$ & 4100 & 100 & {$[8]$} \\
\hline
\end{tabular}

*Value computed using eqn (1).

Table 3: Summary of available JWL's for dynamite in literature.

\begin{tabular}{|c|c|c|c|}
\hline & $\begin{array}{c}\text { Unigel } \\
\text { Penn et al. [6] }\end{array}$ & $\begin{array}{c}\text { Unigel } \\
\text { Hornberg [5] }\end{array}$ & $\begin{array}{c}\text { Unigel } \\
\text { Edwards et al. [4] }\end{array}$ \\
\hline$\rho_{\mathbf{0}} \mathbf{( g / c c )}$ & 1.262 & 1.294 & 1.26 \\
\hline $\mathbf{P}_{\mathbf{C J}}(\mathbf{G P a})$ & 12.0 & 12.0 & 12.8 \\
\hline $\mathbf{D}_{\mathbf{C J}}(\mathbf{m} / \mathbf{s})$ & 5760 & 5477 & 5760 \\
\hline $\mathbf{E}_{\mathbf{0}}(\mathbf{k J} / \mathbf{c c})$ & 5.1 & 5.1 & 4.04 \\
\hline$\Gamma$ & 2.49 & Not Reported & 2.49 \\
\hline $\mathbf{A}(\mathbf{G P a})$ & 190.7 & 121.831 & 109.70 \\
\hline $\mathbf{B} \mathbf{( G P a )}$ & 7.58 & 1.857 & 7.58 \\
\hline $\mathbf{R}_{\mathbf{1}}$ & 4.4 & 3.60150 & 4.4 \\
\hline $\mathbf{R}_{\mathbf{2}}$ & 1.4 & 0.86185 & 1.4 \\
\hline $\mathbf{\omega}$ & 0.23 & 0.20 & 0.23 \\
\hline $\mathbf{C}(\mathbf{G P a})$ & 0.627 & 0.549 & Not Reported \\
\hline
\end{tabular}

JWL EOS describes the adiabatic expansion of gaseous detonation products. Although the JWL EOS is a mathematical abstraction of the thermochemical processes of detonation, it is sufficient for many engineering analyses and is easily implemented in hydrocodes. The standard form of the JWL EOS is given by Lee et al. [9]

$$
P(V, E)=A\left[1-\frac{\omega}{R_{1} V}\right] e^{-R_{1} V}+B\left[1-\frac{\omega}{R_{2} V}\right] e^{-R_{2} V}+\frac{\omega E}{V}
$$

In this equation, $\mathrm{P}$ is the pressure and $A, B, R_{1}, R_{2}$, and $\boldsymbol{\omega}$ are the JWL coefficients, $V$ is the relative volume which can be computed as $\rho_{\mathrm{o}} / \rho$, where $\rho$ is the current density of the detonation products, and $E$ is the current energy. The coefficients for this EOS are derived from tests in which a cylinder of explosive encased in copper is detonated at one end. The cylinder wall velocity time history is recorded and compared to computational simulations. These simulations are used to back out the JWL coefficients. Table 3 shows some of 
the JWL coefficients for Unigel dynamite found in the literature. In the table, all variables are as defined above and $\mathrm{E}_{\mathrm{o}}$ is the infinite volume energy of detonation.

It is worth briefly discussing the notion of ideality. Penn et al. [6] defines an ideal explosive as one in which there is a constant rate of energy release over a wide range of diameters while Souers et al. [10] defines an ideal explosive as one which follows Zel'dovich-von Neumann-Doring (ZND) theory and possesses a true CJ point under heavy confinement. Powerful military explosives like PETN are ideal explosives. Composite explosives like dynamite and ANFO, typically do not display these characteristics. Penn et al. [6] noted that, while ANFO's behaviour was highly complex and would require a more complex equation of state, dynamite could be approximated as an ideal explosive and thus the JWL EOS could be used.

It is interesting to note that the energy (or heat of explosion) provided by Dyno Nobel for Unigel in Table 1 is similar to the $E_{o}$ value for two of the coefficient sets listed in Table 3. Penn et al. [6] explicitly states that their $\mathrm{E}_{\mathrm{o}}$ value was based on the heat of formation of the detonation products at the CJ state, but Hornberg [5] and Edwards et al. [4] do not provide a clear indication of how they arrived at their energy values. $E_{0}$ is important to the JWL formulation because it is used to make the energy of the JWL consistent with the explosive's available energy.

\section{Scaling JWL coefficients}

The experimental program described in this paper made use of Unimax, for which no formal EOS data exists. One simple method of generating JWL coefficients for an uncharacterized explosive like Unimax is to use its density to scale the JWL coefficients for another similar explosive. There are, however, very few methods available for engineers to perform such a scaling procedure. For very small adjustments, one density based adjustment method, as presented in Souers et al. [10], may be used. Small density adjustments of this type are typically required when analyzing multiple shots of the same explosive during a test series. In Lee et al. [9], where the JWL is first presented, the authors provide another method of scaling JWL coefficients based on density for changes on the order of $10 \%$. While the density scaling used in this article is approximately $15 \%$, this latter method was still employed to investigate its applicability. Although it would be possible to use advanced thermochemical equilibrium codes as another method of generating JWL coefficients, such tools are not generally available to the public.

The scaling procedure can be described as follows. The original $\Gamma$ value, the new unreacted density, and the new detonation velocity are used to compute the new CJ pressure. The original $\mathrm{E}_{\mathrm{o}}$ is linearly scaled by the ratio of new to original density to obtain the new $\mathrm{E}_{0}$. The original values of $\mathrm{R}_{1}, \mathrm{R}_{2}, \Gamma$, and $\boldsymbol{\omega}$ are used in conjunction with the new values of $E_{o}$ and $P_{C J}$ to solve three simultaneous equations that relate pressure, relative volume, and energy. The results of the solution of this system of equations are new values of $A, B$, and $C$. The full procedure is well documented in Lee et al. [9]. 
Table 4: Original and adjusted JWL coefficients.

\begin{tabular}{|c|c|c|}
\hline & $\begin{array}{c}\text { Unigel } \\
\text { Penn et al. [6] }\end{array}$ & Adjusted Unimax \\
\hline$\rho_{\mathbf{0}}(\mathbf{g} / \mathbf{c c})$ & 1.262 & 1.50 \\
\hline $\mathbf{P}_{\mathbf{C J}}(\mathbf{G P a})$ & 12.0 & 14.7 \\
\hline $\mathbf{D}_{\mathbf{C J}}(\mathbf{m} / \mathbf{s})$ & 5760 & 5856 \\
\hline $\mathbf{E}_{\mathbf{0}}(\mathbf{k J} / \mathbf{c c})$ & 5.1 & 6.1 \\
\hline$\Gamma$ & 2.49 & 2.49 \\
\hline $\mathbf{A}(\mathbf{G P a})$ & 190.7 & 234.4 \\
\hline $\mathbf{B}(\mathbf{G P a})$ & 7.58 & 9.51 \\
\hline $\mathbf{R}_{\mathbf{1}}$ & 4.4 & 4.4 \\
\hline $\mathbf{R}_{\mathbf{2}}$ & 1.4 & 1.4 \\
\hline $\mathbf{\omega}$ & 0.23 & 0.23 \\
\hline $\mathbf{C}(\mathbf{G P a})$ & 0.627 & 0.716 \\
\hline
\end{tabular}

The three sets of JWL coefficients from the literature listed in Table 3 were compared to the Unigel currently manufactured by Dyno Nobel (see Table 1). The first two have similar energies $\left(E_{0}\right)$ while the third is significantly lower. The third set was therefore discarded. The second set of coefficients from Hornberg [5] had unusual values for $R_{1}$ and $R_{2}$, and this caused the adjustment method to produce a negative value for $\mathrm{B}$, which was unacceptable. The second set was also discarded. The adjustment scheme described above was therefore directly applied to the JWL coefficients from Penn et al. [6]. While the manufacturer supplied heat of explosion and the JWL $\mathrm{E}_{\mathrm{o}}$ for Unigel compare favourably, there is no indication that Unimax's $\mathrm{E}_{\mathrm{o}}$ should also be closely related to the heat of explosion. Without any further knowledge, the original $\mathrm{E}_{\mathrm{o}}$ for Unigel was scaled based on the density ratio, rather than directly specifying the energy. The results of the JWL coefficient scaling procedure are provided in Table 4. This set of adjusted JWL parameters will be used to model the airblast from the experimental program.

\section{Experiment design}

The dynamite charges were detonated in two separate rooms of an unreinforced brick masonry building. Figures 1 and 2 show plan views of Blast Chambers A and $\mathrm{B}$, respectively. The drawings show the locations of the charge and sensors in each blast chamber; sensor elevations are measured relative to the finished floor of the chambers. In both locations, the chamber walls were instrumented with piezoelectric pressure transducers manufactured by PCB Piezotronics (Depew, New York). The transducers were flush mounted on prefabricated metal plates mounted to the interior surface of the chamber walls. The instruments were powered and data recorded by National Instruments 4472 modules sampling at $100 \mathrm{kHz}$ with 24 bit resolution. 

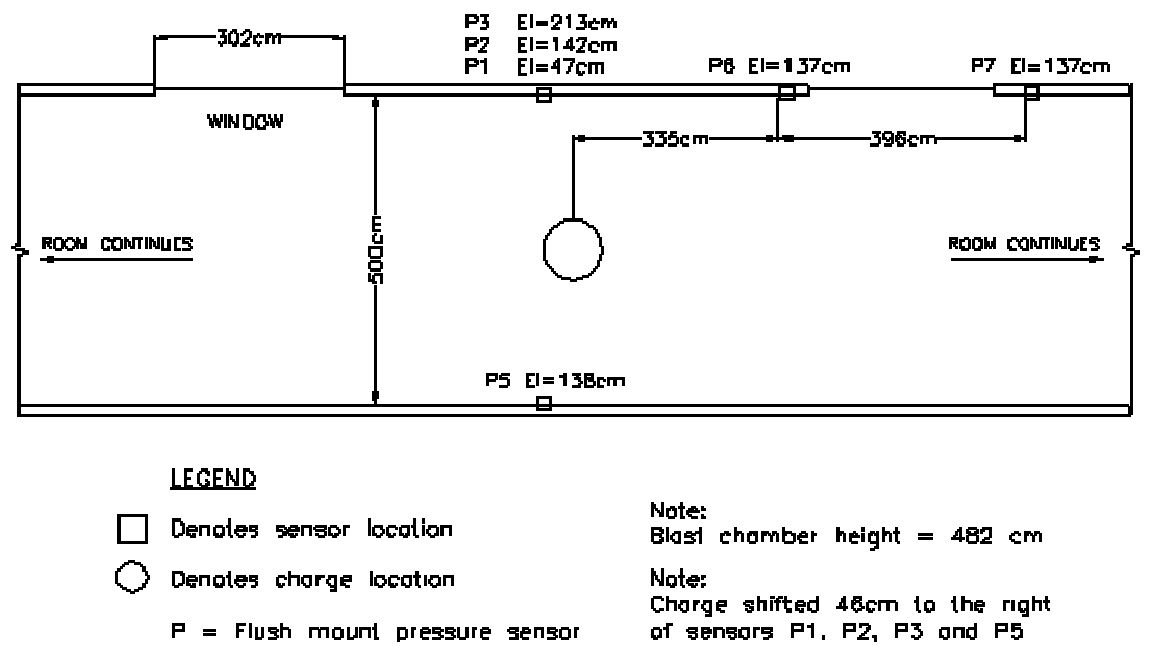

Figure 1: $\quad$ Plan view of Blast Chamber A.

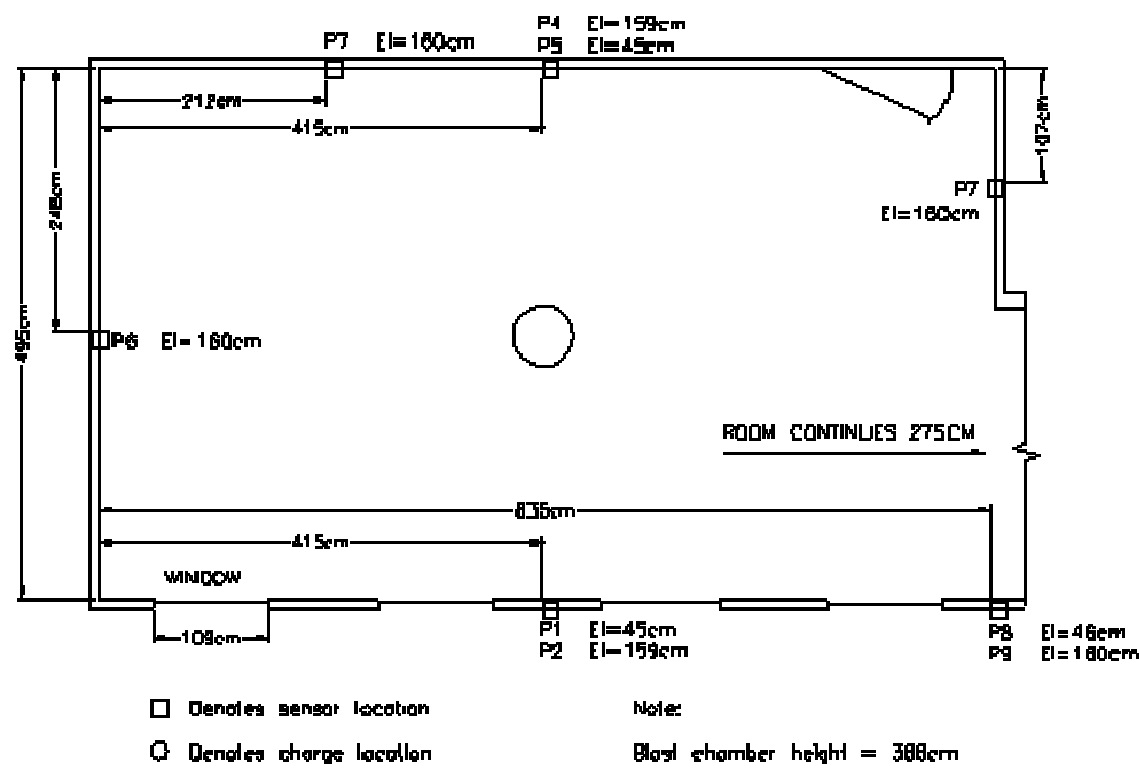

$P$ - Flugh moun preggure senger

Figure 2: $\quad$ Plan view of Blast Chamber B.

The charge in Blast Chamber A was $6.53 \mathrm{~kg}$ and the charge in Blast Chamber B was $8.71 \mathrm{~kg}$ of Unimax sticks formed into upright cylinders. The charges were designed to damage, but not totally collapse the walls in each chamber. The height of both charges was approximately $41 \mathrm{~cm}$. At detonation, the bottoms 
of the charges were at a height of $30 \mathrm{~cm}$ relative to the finished floor of the blast chamber. Both charges were detonated at their centres of mass with two instant electric blasting caps.

\section{Airblast modelling}

Airblast modelling was performed using CTH, a three dimensional shock physics code written and maintained by Sandia National Laboratories (McGlaun et al. [11]). Simulations were performed using the built in JWL EOS. The detonation was modelled using the HEBURN feature of CTH. HEBURN allows the user to specify a detonation point and detonation velocity. The code then automatically handles the insertion of energy into the mesh to simulate detonation. In order to use the code's JWL EOS, the user supplies CTH with the constants A, B, $\boldsymbol{\omega}, \mathrm{R}_{1}$, $\mathrm{R}_{2}, \mathrm{P}_{\mathrm{JC}}, \mathrm{D}_{\mathrm{CJ}}$, and $\rho_{\mathrm{o}}$. The code then computes all other necessary quantities automatically and performs a check to ensure that the specified JWL coefficients are consistent with the specified $\mathrm{CJ}$ state.

The simulation was performed in 2D axisymmetric cylindrical coordinates. Thus the explosive was placed at the centre of the mesh, and a symmetric boundary was defined through the centre of the charge. This symmetry combined with the use of adaptive mesh refinement (AMR) permitted highly resolved simulations. AMR was controlled using two refinement indicators, one which tracked high pressure gradients and the other which predicted the kinetic energy errors associated with unrefinement. The explosive material and the air shock were both zoned at $0.16 \mathrm{~cm}$. A convergence study showed that this meshing scheme provided reasonably accurate pressures and very accurate impulses. The air used in the simulations was adjusted to account for atmospheric conditions at the time of the test. There was significant venting area in both blast chambers, so gas phase pressure was not observed in the experimental data. Interior shock reflections were however observed. In order to facilitate the 2D modelling effort, pressure and impulse comparisons were made for only the first reflection of the shock front. Furthermore, the slight angle of incidence (approximately 10 degrees) of the sensors in shot A relative to the charge will be ignored as its effect on the results is relatively insignificant.

\section{Results}

Airblast simulations of the two experiments were performed using the JWL parameters listed in Table 4 and the modelling techniques described in the previous section. Tables 5 and 6 compare experimental and predicted pressures and impulses in each blast chamber. Note that experimental and predicted impulses were computed as the time integrals of the pressure-time histories. The tables show that, in general, predicted and experimental impulses compared well. The average impulse error was roughly 17 percent considering the comparisons in both blast chambers. Maximum reflected pressures, as expected, did not agree as well. On average, the error between experimental and predicted reflected pressures was 39 percent. 
Table 5: Comparisons of experimental and predicted pressures and impulses from Blast Chamber A. Cell size of $0.16 \mathrm{~cm}$.

\begin{tabular}{|c|c|c|c|c|}
\hline $\begin{array}{c}\text { Sensor } \\
\text { Location }\end{array}$ & $\begin{array}{c}\text { Exp. Pressure } \\
\text { (MPa) }\end{array}$ & $\begin{array}{c}\text { Pred. Pressure } \\
\text { (MPa) }\end{array}$ & $\begin{array}{c}\text { Exp. Impulse } \\
\text { (MPa ms) }\end{array}$ & $\begin{array}{c}\text { Pred. Impulse } \\
\text { (MPa ms) }\end{array}$ \\
\hline P1 & 5.44 & 4.06 & 1.25 & 1.39 \\
\hline P2 & 2.33 & 1.09 & 0.627 & 0.552 \\
\hline P3 & 0.814 & 0.386 & 0.331 & 0.400 \\
\hline P5 & 2.30 & 1.17 & 0.724 & 0.572 \\
\hline
\end{tabular}

Table 6: Comparisons of experimental and predicted pressures and impulses from Blast Chamber B. Cell size of $0.16 \mathrm{~cm}$.

\begin{tabular}{|c|c|c|c|c|}
\hline $\begin{array}{c}\text { Sensor } \\
\text { Location }\end{array}$ & $\begin{array}{c}\text { Exp. } \\
\text { Pressure } \\
\text { (MPa) }\end{array}$ & $\begin{array}{c}\text { Pred. } \\
\text { Pressure } \\
\text { (MPa) }\end{array}$ & $\begin{array}{c}\text { Exp. } \\
\text { Impulse } \\
\text { (MPa ms) }\end{array}$ & $\begin{array}{c}\text { Pred. } \\
\text { Impulse } \\
\text { (MPa ms) }\end{array}$ \\
\hline P1 & 11.0 & 7.79 & 1.26 & 1.90 \\
\hline P2 & 1.50 & 1.21 & 0.593 & 0.614 \\
\hline P4 & 1.85 & 1.21 & 0.627 & 0.614 \\
\hline P6 & 1.06 & 0.579 & 0.565 & 0.496 \\
\hline
\end{tabular}

The highest observed impulse error was for sensor P1 in Blast Chamber B. Table 6 shows that $\mathrm{CTH}$ predicts almost twice the impulse recorded during the experiment. If one considers that charge B was almost $2.2 \mathrm{~kg}$ larger than charge A and the height of sensor P1 in each location was nearly the same, then it would be logical for the P1 sensor in shot B to record a higher impulse than in shot A. Looking at sensor P1 in Tables 5 and 6, however, this is clearly not the case. This would suggest an incomplete detonation of shot B or a malfunction of the P1 sensor for this shot. However, a definitive conclusion regarding the source of this error cannot be drawn from the experimental data alone.

\section{Conclusion}

The JWL coefficients for dynamite available in the literature were reviewed and the closest match to currently produced dynamites was selected. This set of JWL coefficients was used along with a density adjustment procedure to arrive at a set of JWL coefficients for a previously uncharacterized dynamite, Unimax. The adequacy of the JWL parameters adjusted to model Unimax was examined by pressure and impulse comparisons to the experimental results of two blast tests. Tables 5 and 6 show that experimental and predicted impulses compared well, but reflected pressures did not.

Typically, maximum reflected pressures are more difficult to accurately simulate than reflected impulses since a much finer mesh is required to capture peak reflected pressures. However, a number of other factors could have contributed to the error in pressure comparisons. First, the JWL coefficients for Unimax were based on scaling Unigel's parameters. While Unigel and Unimax are both nitroglycerin dynamites, Table 1 shows that the makeup of their 
oxidizers (ammonium nitrate and sodium nitrate) varies considerably. The scaling procedure used in this work can only account for the effect of density and thus chemical makeup will not be taken into account unless separately considered. Another possible contributing factor is that the charges were bundled sticks of dynamite, rather than a large diameter monolithic charge. The behaviour of a bundled charge relative to the typical case of a monolithic charge has not been investigated.

Despite the pressure errors observed in these simulations, the use of $\mathrm{CTH}$, coupled with the modified JWL coefficients for Unimax, provided reasonably accurate predictions of the impulses observed during the experimental program. Even though a more accurate JWL definition could better model blast pressures, the JWL coefficients presented in this work are sufficient for engineers to use in computing blast loads for mechanics analyses that are impulse dominated.

\section{References}

[1] United States Army Corps of Engineers, Design and Analysis of Hardened Structures to Conventional Weapons Effects, UFC 3-340-01.

[2] Cooper, Paul W., Explosives Engineering, Wiley: New York , 1996.

[3] LeVan, B., Personal communication, January 2007, Dyno Nobel, Salt Lake City, Utah.

[4] Edwards, C.L., Pearson, D. Craig and Baker, Diane F., Draft Ground Motion Data from the small-scale explosive experiments conducted at the grefco perlite mine near socorro, New Mexico. Report No. LA-UR-941003, Los Alamos National Laboratory, 1994.

[5] Hornberg, H., Determination of fume state parameters from expansion measurements of metal tubes, Propellants, Explosives, and Pyrotechnics 11(1), pp. 23-31, 1986.

[6] Penn, Lynn, et al., Determination of equation-of-state parameters for four types of explosive. Report No. UCRL-51892, Lawrence Livermore Laboratory, 1975.

[7] Souers, P. Clark, et al. The effects of containment on detonation velocity, Propellants, Explosives, and Pyrotechnics 29(1), pp.19-26, 2004.

[8] Sadwin, Lippe D. and Junk, Norman M., Lateral Shock Pressure Measurements at an explosive column. Fourth Symposium on Detonation, US Naval Ordnance Laboratory: White Oak, Maryland, pp. 92-95, 1965.

[9] Lee, E.L., Hornig, H.C. and Kury, J.W. Adiabatic Expansion of High Explosive Detonation Products. Report No. UCRL-50422, Lawrence Radiation Laboratory, 1968.

[10] Souers, P.C., Wu, Ben and Haselman, L.C. Detonation Equation of State at LLNL, 1995. Report No. UCRL-ID 119262 Rev 3, Lawrence Livermore National Laboratory, 1996.

[11] McGlaun, J.M. and Thompson, S.L., CTH: A three-dimensional shock wave physics code, International Journal of Impact Engineering 10(1-4), pp.351-360, 1990. 